\title{
Crystal structures and dielectric responses of guanidinium - sulfonate salts
}

Takahiro Kobayashi $^{1}{ }$, Norihisa Hoshino ${ }^{1}$, Takashi Takeda ${ }^{1}$, Tomoyuki Akutagawa ${ }^{1}$

${ }^{1}$ Graduate School Of Engineering, Tohoku University, Sendai, Japan E-mail: tkoba@mail.tagen.tohoku.ac.jp

Ferroelectric property has been reported in simple organic cation-anion salt of guanidinium $\mathrm{C}\left(\mathrm{NH}_{2}\right)_{3}{ }^{+}$aluminum sulfate hexahydrate. Six hydrogen-bonding protons of planar $\mathrm{C}\left(\mathrm{NH}_{2}\right)_{3}{ }^{+}$cation has been utilized for the construction of supramolecular cation-anion structures. Large number of layered $\mathrm{C}\left(\mathrm{NH}_{2}\right)_{3}{ }^{+}$salts have been prepared by conventional combining with various type of sulfonate anions, in which $-\mathrm{SO}_{3}{ }^{2-}$ unit is topologically fitted with $\mathrm{C}\left(\mathrm{NH}_{2}\right)_{3}{ }^{+}$cation.

Among them, simple salt of $\mathrm{C}\left(\mathrm{NH}_{2}\right)_{3}{ }^{+}\left(\mathrm{C}_{2} \mathrm{H}_{5} \mathrm{O}-\mathrm{SO}_{3}{ }^{-}\right)$showed the ferroelectricity through the molecular rotation of $\mathrm{C}_{2} \mathrm{H}_{5} \mathrm{O}-$ group in anions.[1] Herein, we prepared simple $\mathrm{C}\left(\mathrm{NH}_{2}\right)_{3}{ }^{+}\left(\mathrm{R}-\mathrm{SO}_{3}{ }^{-}\right)$with $\mathrm{R}=\mathrm{CH}_{3}, \mathrm{C}_{2} \mathrm{H}_{5}, \mathrm{C}_{2} \mathrm{HF}_{4}, \mathrm{C}_{4} \mathrm{~F}_{9}, \mathrm{C}_{4} \mathrm{~F}_{9} \mathrm{O}$, whose phase transition behaviors and molecular arrangements were examined by single crystal X-ray diffraction analyses and DSC analyses in the temperature range from $173 \mathrm{~K}$ to melting point and temperature-dependent dielectric constants were measured at the frequencies range from 100 to $1000 \times 10^{3} \mathrm{~Hz}$.

$1: 1$ salts of $\mathrm{C}\left(\mathrm{NH}_{2}\right)_{3}{ }^{+}\left(\mathrm{C}_{2} \mathrm{H}_{5}-\mathrm{SO}_{3}{ }^{-}\right)$(1) and $\mathrm{C}\left(\mathrm{NH}_{2}\right)_{3}{ }^{+}\left(\mathrm{CH}_{3}-\mathrm{SO}_{3}{ }^{-}\right)$(2) were obtained as centrosymmetrical space group of $\mathrm{C} 2 / \mathrm{m}$. Two-dimensional hydrogen-bonding sheet structure was observed in the ab plane, which was stacked along the $\mathrm{C}$ axis. The DSC chart of salt $\mathbf{1}$ showed the reversible peaks around $310 \mathrm{~K}$, which was consistent with the transition entropy $(\Delta S)$ for the order-disorder type phase transition. On the contrary, there was no peaks in DSC chart of salt $\mathbf{2}$. The real part dielectric constant $\varepsilon_{1}$ of salt $\mathbf{1}$ in the pellet also indicated the response around $310 \mathrm{~K}$, whereas there was no dielectric

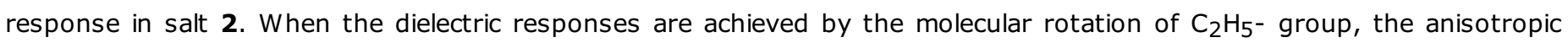
dielectric responses should be observed in single crystalline salt $\mathbf{1}$. Actually, the dielectric responses of single crystalline $\mathbf{1}$ showed no response along the ab plane (//ab), whereas the dielectric response was observed along the bc plane (//bc). Therefore, the dielectric response found in salt $\mathbf{1}$ was dominated by the molecular rotation of $\mathrm{C}_{2} \mathrm{H}_{5}-\mathrm{group}$. The phase transition, crystal structure, and dielectric response of the other guanidine-sulfonate salts will be discussed.

[1] Szafrański, M.; and Jarek, M. (2008). J. Phys. Chem, B. 112, 3101-3109.

[2] Russell, V. A. et al. (1994). J. Am. Chem. Soc, 116, 1941-1952.
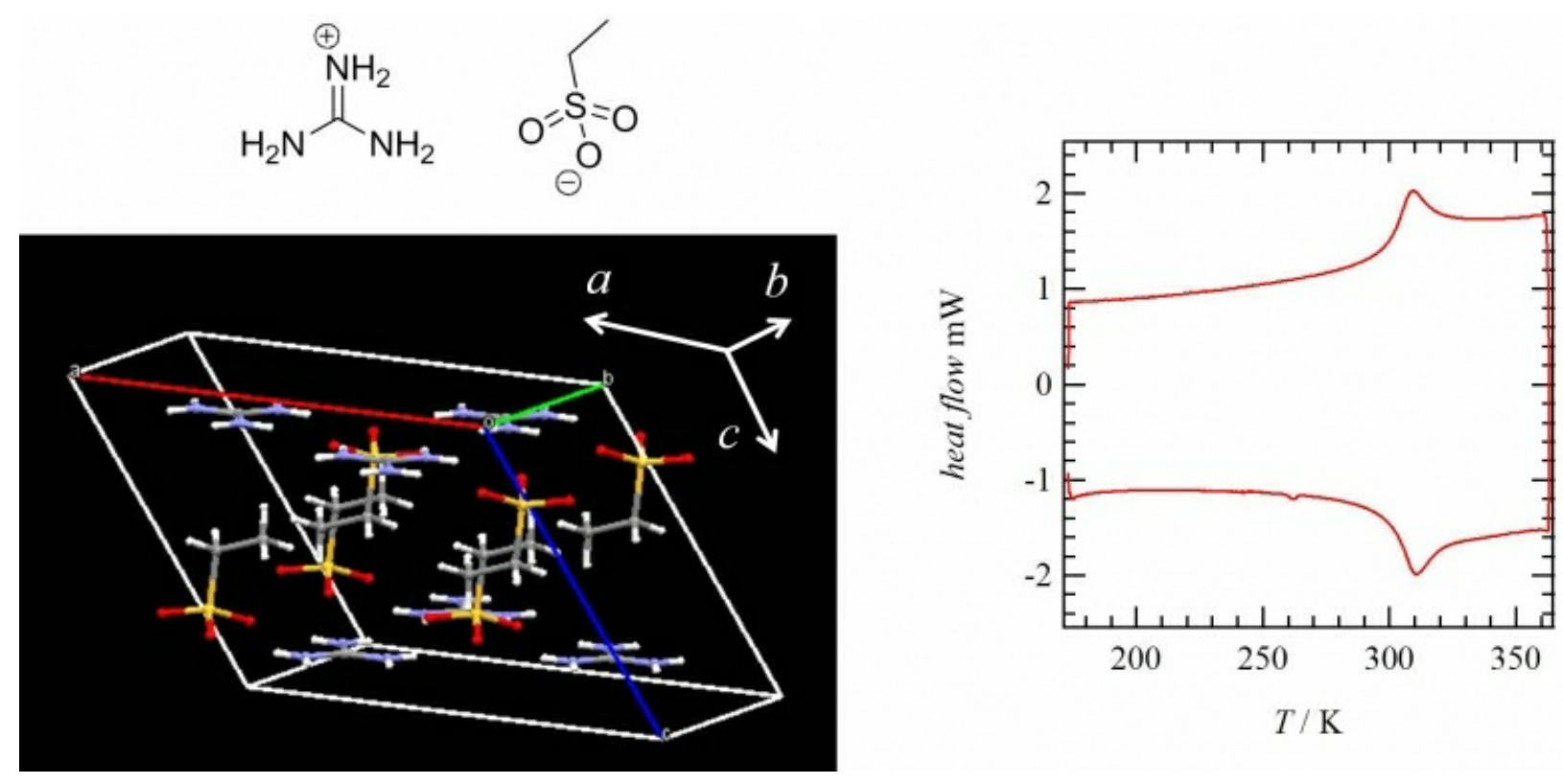

Keywords: Guanidinium, Phase Transition, Molecular Rotator 